\title{
Dialética da psicopatia
}

Gustavo Bonini Castellana ${ }^{1}$

\section{Resumo}

O estudo dos transtornos da personalidade na psiquiatria contemporânea tem demonstrado amplas limitações de compreensibilidade quando restrito à perspectiva sintomatológica-criteriológica. Neste artigo pretende-se ampliar as possibilidades de compreensão dos fenômenos apreendidos nos casos de transtorno da personalidade a partir da análise do encontro com dois pacientes. Para tal, se faz necessária primeiramente uma delimitação do conceito de anormalidade no estudo das personalidades e, para esta, utilizaremos as noções de normal e patológico propostas por Canguilhem. Em seguida, espera-se, já dentro do campo das personalidades patológicas, ampliar as possibilidades de compreensão da experiência vivida por indivíduos intitulados psicopatas, referenciando-nos pela tipologia dialética de Blankenburg. Dessa forma, este artigo objetiva expandir a ainda tímida contribuição da perspectiva fenomenológica no campo de estudos psicopatológicos dos transtornos da personalidade.

Palavras-chave: Psicopatia; Transtorno de Personalidade; Fenomenologia; Dialética.

\section{Dialectic of Psychopathy}

\begin{abstract}
The study of personality disorders in contemporary psychiatry has demonstrated extensive shortcomings of understandability when restricted to the symptomatological-criteriological approach. In this article we intend to

\footnotetext{
${ }^{1}$ Psiquiatra do Programa de Psiquiatria e Psicologia Forense do IPq-HCFMUSP. Membro da Sociedade Brasileira e Psicopatologia Fenômeno-Estrutural. Email: gbcastellana@yahoo.com.br
} 
extend the possibilities of understanding of the phenomena perceived in cases of personality disorder from the analysis of the meeting with two patients. To do this, it is necessary first to delimit the concept of abnormality in the study of personality, using the notions of normal and pathological proposed by Canguilhem. Then, hopefully, already in the field of pathological personalities, expand the possibilities of understanding the lived experience of individuals entitled psychopaths, referring to the typology of dialectics Blankenburg. Therefore, this article aims to expand the still modest contribution of the phenomenological perspective in the field of psychopathological studies of personality disorders.

Keywords: Psychopathy; Personality Disorder; Phenomenology; Dialectic.

\section{Transtornos da personalidade:}

\section{limites do diagnóstico criteriológico-sintomatológico}

O termo psicopatia foi cunhado por Kraepelin como sinônimo de inibição do desenvolvimento da personalidade em 1904 (Kraepelin, 1904, como citado em Shine, 2005). Em 1923, Schneider (1943) lança as "Personalidades Psicopaticas" utilizando o termo como sinônimo do que hoje chamamos de "Transtornos da personalidade", reservando o termo "psicopatas desalmados" para o que hoje seriam os psicopatas propriamente ditos.

Atualmente, o termo psicopatia não aparece nos manuais diagnósticos em função da ambiguidade de significados gerados pelo termo, ora designando "Transtorno de personalidade" lato sensu, ora designando "Transtorno da personalidade anti-social". No entanto, o termo ainda é utilizado na prática psiquiátrica forense na maior parte das vezes como sinônimo de "Transtorno da personalidade anti-social". A psicopatia apresenta instrumentos específicos para o diagnóstico, sendo o principal deles a PCL-R (Psychopathy ChecklistRevised), desenvolvido por Hare (1991), com o objetivo de determinar o risco de reincidência criminal entre delinquentes. Neste artigo, utilizaremos o termo psicopatia aproximando-o do que chamamos atualmente de transtorno da personalidade anti-social, por acreditarmos que desta forma estaremos mais próximos da concepção original do transtorno associado ao termo. 
As frequentes mudanças da nomenclatura e da definição dos transtornos mentais não são, no entanto, exclusivas dos transtornos da personalidade, e mudanças têm ocorrido em outros diagnósticos presentes na CID-10 (OMS, 1993) e DSM-IV (APA, 2002) também.

Tais mudanças têm como objetivo, em tese, dar maior confiabilidade aos diagnósticos apontados. O sujeito que sofre de depressão, por exemplo, apresentará anedonia, tristeza e sentimento de menos valia em qualquer parte do mundo, entre observadores de diferentes orientações psicopatológicas.

Mas, se de um lado os diagnósticos pautados em critérios e sintomas buscam dar confiabilidade, isto é, a qualidade de reprodutibilidade às entidades nosográficas codificadas, esbarram nos limites da validade diagnóstica, isto é, o grau pelo qual um instrumento utilizado na mensuração é capaz de determinar o verdadeiro valor daquilo que está sendo medido.

Para Kraus, os critérios utilizados nos glossários foram selecionados mais pela definibilidade do que pelo foco na essência da entidade psicopatológica. “O resultado é que nem o critério utilizado nem o diagnóstico chegam próximo à essência do fenômeno ao qual se refere", explica Kraus (2003, p. 204).

Tal limitação fica ainda mais evidente nos diagnósticos de "Transtornos da personalidade". Exemplo claro está no conceito de psicopatia: ainda que não seja um conceito validado nos manuais americanos e internacionais, sabe-se que este é um termo utilizado demasiadamente entre os psiquiatras, de forma que qualquer um pode ser chamado de "psicopata": o adolescente infrator, o "serial killer", um político corrupto, o borderline, um colega de trabalho desleal. $\mathrm{Na}$ ausência de melhor teoria que nos ajude a compreender tais comportamentos, acaba se fazendo um uso irrestrito do termo "psicopata".

De qualquer forma, não é ambição deste estudo a construção de uma nova nosografia ou estabelecer (mais) uma crítica fervorosa às classificações oficiais internacionais, como a CID-10 (OMS, 1993) e o DSM-IV (APA, 2002), até porque esta tarefa já se tornou uma rotina em qualquer roda de discussão psicopatológica, e provavelmente haveria pouco a contribuir se nos restringíssemos a esta tarefa.

Também não é escopo deste trabalho assumir as condições biográficas ou determinantes socioculturais da manifestação de comportamentos anormais ou patológicos, ainda que acreditemos na importância de estudos desta natureza. Este estudo ambiciona tão somente aventurar-se pela árdua tarefa de conhecer a essência da experiência vivida pelos sujeitos diagnosticados com transtornos da personalidade de acordo com os critérios sintomatológicos propostos pela CID- 
10 e DSM-IV. Por essências entenderemos aqui, como definido por Kraus, como sendo "as características invariáveis de algo dado na experiência, como, por exemplo, as características invariáveis de todas as árvores, ao invés da característica de uma árvore particular" (Kraus, 2003, p. 201).

Delimita-se, assim, o campo fenomenológico onde se insere este estudo. Faz-se necessário agora delimitar alguns axiomas da fenomenologia que serão utilizados ao longo deste trabalho, antes de adentrarmos especificamente nos transtornos da personalidade.

\section{Psicopatologia fenomenológica: o estudo do encontro}

De acordo com Lanteri-Laura (1982), fenomenologia foi um termo cunhado por Lambert em 1764 para significar "o estudo das aparências", se referindo à descrição empírica da experiência humana, e Hegel retomou o termo utilizando-o como o estudo da maneira pela qual a experiência se manifesta. Husserl, Heidegger, Merleau-Ponty, Jaspers e finalmente Minkowski redefiniram progressivamente o conceito, estes últimos aproximando-o da prática psiquiátrica.

O autor explica ainda que a psiquiatria fenomenológica não propõe mais uma teoria psiquiátrica, mas uma evidente e rigorosa elucidação do conhecimento e do saber-fazer que funcionam na psiquiatria efetiva.

Tatossian (2006, p. 36) reforça esta ideia, dizendo que

a fenomenologia não pretende explicar, mas clarificar a experiência psiquiátrica, ou seja, torná-la transparente quanto à essência, ou a isto que o psiquiatra sabe desde sempre, mas não sabe forçosamente que sabe. Não se trata da experiência dos estados de fato novos, mas da experiência nova sobre o que e em quem se é desde sempre objeto da experiência. Trata-se aqui de um caminho puramente descritivo que não fornece fundamentalmente nada de novo.

Kraus (1994) argumenta que a psiquiatria fenomenológica-antropológica aventura-se não só a entender o fenômeno psicopatológico comparando-o ao fenômeno psicológico normal, mas também procura conceber os distúrbios psiquiátricos como modificações das estruturas essenciais do ser-no-mundo. 
Sabe-se, no entanto, que esta não é uma tarefa simples. Thomas Nagel (1991), em um famoso artigo de 1974, intitulado "What is it like to be a bat?" (traduzido como "como é ser um morcego?"), postula que o caráter subjetivo da experiência caracteriza-se pela possibilidade de existir algo que é ser este organismo, algo que é como ser para este organismo. No entanto comenta assim a dificuldade inerente ao acesso à subjetividade:

Há um sentido no qual os fatos fenomenológicos [phenomenological facts] são perfeitamente objetivos: uma pessoa pode conhecer ou falar sobre a qualidade das experiências do outro. Elas são subjetivas, no entanto, no sentido em que mesmo essa atribuição objetiva de experiência só é possível para alguém suficientemente similar ao objeto da atribuição para estar apto a adotar o seu ponto de vista, para compreender a atribuição na primeira pessoa tão bem quanto na terceira, por assim dizer. Quanto mais diferente de nós for o outro sujeito da experiência, menos sucesso se pode esperar desse empreendimento. No nosso próprio caso, ocupamos o ponto de vista relevante, mas teremos tanta dificuldade em compreender apropriadamente a nossa própria experiência se a abordarmos a partir de um outro ponto de vista, quanto teríamos se tentássemos compreender a experiência de uma outra espécie sem que adotássemos o seu ponto de vista. (Nagel, 1991, p. 253)

Sugere, assim, que "seria mais acurado pensar na objetividade como uma direção em que o entendimento pode mover-se" (Nagel, 1991, p. 261).

Entendemos que a busca desta objetividade e, portanto, do entendimento em psicopatologia se dá pela análise da intersubjetividade presente no encontro com o paciente.

Como sugerido por Lanteri-Laura, “a investigação da semiologia deveria se concentrar especialmente no estudo do encontro, não através de efusões românticas e insight sobre a consciência do outro, mas através das manifestações dos sinais presentes na relação com a pessoa" (Lanteri-Laura, 1982, p. 60).

Uma última consideração necessária, antes de adentrarmos na fenomenologia dos transtornos da personalidade, é a de que acreditamos, como pressuposto desta teorização, que seja possível uma aproximação da subjetividade do ser-no-mundo do sujeito que se nos apresenta. Tal axioma deve ser considerado para a prática fenomenológica. Foge ao escopo deste trabalho, no entanto, determinar as vias pelas quais estabelecemos tal 
pressuposto, dado que é matéria de diversos outros estudos do campo da fenomenologia, como no trabalho "O contato interpessoal na perspectiva fenomenológica"(Castellana, 2008).

\section{Personalidade normal e patológica}

Discutir a existência, a validade ou a definição dos transtornos da personalidade implica em caminhar por um terreno arenoso, já que esbarramos invariavelmente em um tema caro aos estudiosos de psicopatologia: o conceito do que é normal e o que é patológico. Os transtornos de personalidade parecem ocupar um lugar privilegiado nesta polaridade, já que expressam dentro da própria psiquiatria os transtornos em que estes limites estão ainda mais borrados.

O conceito de personalidade traz em si um padrão global de ser, agir, pensar, sentir e demais qualidades que são únicas de cada indivíduo, e portanto uma análise comparativa de um indivíduo com ele mesmo e seu modo único de ser traz uma dificuldade ímpar dentro do estudo de psicopatologia.

Segundo Otto Dorr (1995), são duas as características centrais daquilo que chamamos de personalidade: o fenômeno da permanência através do tempo e a dialética entre identidade de si mesmo e identidade de papel. Somos sempre a mesma pessoa apesar da maturação, do passar dos anos, das mudanças que trazem consigo a dor. Em rigor, "se é" uma personalidade, mais do que "se tem" uma personalidade" (p. 472).

No entanto, ainda que os modos de ser-no-mundo sejam infinitos, e que possam existir variâncias peculiares à época ou meio sociocultural onde se inserem, acreditamos que alguns tipos psicológicos assumem uma relativa estabilidade ao longo do tempo e que entre estes alguns possam ser caracterizados como personalidades patológicas em virtude de sua tendência a manter características repulsivas em relação ao meio onde vivem, como explicaremos abaixo.

Em sua tese "O normal e o patológico", Canguilhem (2009) diz que a fronteira entre o normal e o patológico é imprecisa para diversos indivíduos considerados simultaneamente, mas é perfeitamente precisa para um único e mesmo indivíduo considerado sucessivamente. 
Acredita que o doente deva sempre ser julgado em relação à situação à qual ele reage e com os instrumentos de ação que o meio próprio lhe oferece, como esclarece aqui:

Assim, há dois tipos de comportamento inéditos na vida. Há os que se estabilizam em novas constantes, mas cuja estabilidade não constituirá obstáculo a uma nova superação eventual. Trata-se de constantes normais de valor propulsivo. São realmente normais por normatividade. E há os que se estabilizam sob formas de constantes que o ser vivo se esforçará, ansiosamente, por preservar de qualquer perturbação eventual. Trata-se ainda de constantes normais, mas de valor repulsivo, exprimindo, nelas, a morte da normatividade. Nisso, estas constantes são patológicas, apesar de normais enquanto nelas puder viver o ser vivo. (Canguilhem, 2009, p.158)

$\mathrm{O}$ autor define ainda a diferença entre o estado fisiológico e o estado patológico:

O estado fisiológico identifica-se com o estado são, mais ainda que com o estado normal. É o estado que pode admitir uma mudança para novas normas. O homem é são, na medida em que é normativo em relação às flutuações de seu meio. Na nossa opinião, as constantes fisiológicas têm, dentre todas as constantes vitais possíveis, um valor propulsivo. Ao contrário, o estado patológico expressa a redução das normas de vida toleradas pelo ser vivo, a precariedade do normal estabelecido pela doença. As constantes patológicas têm valor repulsivo e extremamente conservador. (Canguilhem, 2009, p. 156)

Utilizando-se das noções de Canguilhem, podemos estabelecer que uma personalidade é considerada patológica pela perda de sua capacidade de ser normativa em relação ao meio, pelo valor repulsivo de suas características essenciais. Objetivamos, assim, conceber aqui uma noção de personalidade patológica que inclua aqueles que, por seu modo de ser, não apenas "sofram ou façam sofrer", como proposto por Schneider (1943), e que incluiria um valor ideal e um valor normativo, mas que se imobilizem em sua própria incapacidade de auto-transcendência.

As considerações propostas para a definição de personalidade patológica neste trabalho vão de encontro à conceituação de Kraus (2003), que afirma que “o elemento verdadeiramente patológico no transtorno é a capacidade restrita 
de ser de outra maneira, que é este ser-no-mundo alterado e uma relação comprometida com seu próprio modo de ser" (p. 211). O autor lembra que

o anormal, assim como o normal, são localizados em uma ou mais escalas nas quais os desvios podem ocorrer em pelo menos duas direções entre os extremos. Assim, não há normas absolutas, positivamente discriminando o normal do anormal. Ao contrário, as dimensões de desvio são tomadas em consideração de forma que precisam de outro critério pra ser chamada de patológico. (Kraus, 2003, p. 203)

Em acordo com esta concepção, Otto Dorr (1995) defende que a "anormalidade da personalidade ocorre quando estes quadros detêm ou estancam o movimento propulsivo da existência" (p. 479).

Note-se, aqui, que esta incapacidade de transcendência ocorre a partir de um desenvolvimento, no sentido proposto por Jaspers (2005), e por este motivo os transtornos da personalidade não incluem aqueles indivíduos que adquiriram esta incapacidade de transcendência pela imposição de um processo psíquico, como na esquizofrenia - ainda que se possa estudar fenomenologicamente a pessoa do esquizofrênico, como pretendeu Wyrsch (1957).

\section{Tipologia dialética de Blankenburg: o positivo da negatividade}

Existem três pontos de vista das colaborações dentro da perspectiva fenomenológica para o estudo dos transtornos da personalidade: os tipos ideais, introduzidos na psiquiatria por Karl Jaspers, os tipos existenciais, por Binswanger, e as tipologias dialéticas e polaridades, por Blankenburg (Dorr, 1995).

Em que pese a importância da obra de Jaspers e de Binswanger, neste estudo optamos por aprofundar a tipologia dialética proposta por Blankenburg, já que entendemos ser esta de validade ímpar para a compreensão dos transtornos da personalidade.

Deacordo com Dorr (1995), a introdução sistemática do pensamento dialético na psiquiatria foi realizada pelo fenomenólogo alemão Wolfgang Blankenburg, que propunha a busca da positividade do negativo nos transtornos mentais. $\mathrm{O}$ autor acredita que o mais importante de seu aporte é a 
mudança que poderia produzir na relação médico-paciente, argumentando que é muito diferente aproximar-se do paciente com a ideia ou pré-julgamento de que se trata de alguma forma de um deformado ou deficitário, do que chegar a ele sem pré-julgamento algum sobre sua saúde e aberto à possibilidade de ver o positivo de sua negatividade, ou em outro momento, o negativo de sua positividade.

Blankenburg (2007) argumenta:

Estamos então diante da questão, quando temos um paciente na nossa frente, seja na visita clínica, na psicoterapia individual, no grupo ou até nas vivência diárias, quais vivências 'patológicas' deste indivíduo são realmente sentidas assim por ele (...) Só é possível falar assim de dialética quando acontece não só uma mudança quantitativa, mas também uma qualitativa. (p. 155)

O autor exemplifica assim a sua proposta:

O acesso ao esquizofrênico é muito difícil se não nos identificarmos, ainda que parcialmente, com o que se passa, sem que nos perguntemos "contra o quê" está se dirigindo esta conduta ou esta vivência que nós experimentamos, em um primeiro momento do contato com o paciente, como uma nova forma de estar no mundo; em suma, se não nos perguntamos pela positividade no negativo, não encontraremos o acesso adequado a ele. (citado por Dorr, 1995, p. 484)

Dorr (1995) reafirma, então, que o importante desta perspectiva é que o desvio para um lado ou outro da polaridade normal-anormal não precisa ser visto como uma carência, mas sim um deslocamento dinâmico da existência contra outro pólo desta polaridade:

Se nos aproximarmos dos histéricos sem preconceitos, a partir desta perspectiva dialética exposta anteriormente, resulta que os traços histéricos aparecem em toda sua positividade. Dessa forma, já não se encara como um desvio com respeito a uma norma presumida, nem sequer o resultado de mecanismos de defesa neuróticos, mas sim como uma busca de um modo de ser que evite o congelamento de seu projeto vital em padrões rígidos de conduta, em sobreidentificação com alguns escassos papéis, e que pela impossibilidade de realizá-los (por circunstâncias alheias a sua vontade) pode mergulhar o sujeito no abismo, como ocorre com os depressivos. (p. 484) 
Seguindo a mesma ideia, Kraus (1987) postula que o modo de ser do histérico tem como estrutura particular a falha na identificação com seu próprio modo de ser (pseudoidentificação). Esta estrutura de não identificação unifica todos os fenômenos, comportamentos, sentimentos, expressões listados nos manuais. Pressupõe, assim, um entendimento da identidade humana como uma relação dialética entre identidade e não-identidade: "a dialética de abandonar identidades e identificar uma nova através da facticidade de ser real de alguém não existe na histeria" (p. 80).

Tais definições vão ao encontro da compreensão original de Jaspers (2005), para quem:

Ao invés de se contentar com seus talentos e possibilidades, o histérico tem a necessidade de aparecer para si mesmo e para os outros como mais do que é, como experimentando mais do que é capaz de experimentar. Isto significa que a pessoa não é o que está fingindo ser. O histérico olha para si mesmo como se houvesse manipulado outros para vê-lo. Ele ilude a si mesmo e aos outros mostrando sentimentos que não tem. Exclusivamente determinado pelos desejos e necessidades, ele vive em um futuro dominador pouco ancorado no passado e no presente. (p. 484)

Assim, enquanto o CID-10 (OMS, 1994) descreve a personalidade histriônica principalmente em termos de comportamento no mundo externo, a tradição fenomenológica inclui a descrição de sua relação consigo mesmo, não só no sentido de ser auto-centrado ou vitimizado, mas também no sentido de auto-engano (Kraus, 2003).

Pretende-se, neste estudo, contribuir para o aprofundamento deste campo, abrindo as possibilidades de compreensão fenomenológica do ser-nomundo vivido por aqueles intitulados psicopatas. Para tal, recorrerei a duas vinhetas clínicas, analisando-as mais especificamente a partir da perspectiva dialética de Blankenburg.

\section{Vinheta clínica I}

Trata-se de um rapaz de 29 anos de idade que me procura no consultório encaminhado por uma colega psicóloga. Antes mesmo do atendimento, ainda na tentativa de conciliarmos um horário para a consulta, surpreendemo-me pelo rápido descarte que faz da consulta frente à sua impossibilidade de 
comparecer naquele horário. Não lhe sendo possível a presença no horário proposto, pede a indicação de um outro psiquiatra que pudesse atendê-lo. Curioso que fico por conhecê-lo, questiono suas possibilidades de agenda e me adequo à sua solicitação, atendendo-o naquele mesmo dia no horário solicitado.

Durante a consulta, quando questionado sobre o encaminhamento, conta que nem sequer conhece a psicóloga que havia sugerido meu nome para atendimento. Apenas havia conseguido o telefone desta em algum site na internet, e ao telefone a mesma rapidamente sugeriu que me procurasse, imaginando que se tratava de um caso que demandava atendimento psiquiátrico primordialmente, segundo contou, mostrando desde já indiferença frente à escolha do profissional com quem se trataria.

Durante a entrevista percebia um contato interpessoal propositadamente sedutor, com expressividade afetiva pouco natural e notadamente direcionada à mobilização do entrevistador, estando sempre atento às minhas reações.

Os dados biográficos corroboraram as impressões iniciais: vínculos afetivos frouxos, frieza emocional, atos impulsivos graves, envolvimento em trapaças no meio profissional e "mentiras descabidas" eram as "queixas" do paciente, muitas destas descritas exatamente nestas palavras, outras facilmente transcritas nos termos aqui presentes. Segundo ele, tais características perduraram por toda a adolescência e vinham assumindo formas mais elaboradas na idade adulta, de forma que dizia se preocupar muito com a ausência de melhora destes "sintomas". Não havianenhum sinal de alterações vivenciais qualitativas ou quantitativas que pudessem sugerir um processo psíquico recente. Negou em seu relatoquaisquer períodos de uso de drogas com características de abuso ou dependência.

Minha consciência frente ao paciente apontava unicamente para a possibilidade de aprendizado naquela vivência, com pouca confiança na possibilidade de realmente ajudá-lo em um processo de psicoterapia. Ao final da consulta, anunciou que não havia se preparado para o comprometimento com honorários, pois "não sabia que devia pagar por uma conversa", e mais uma vez me senti absolutamente destituído de valores naquela situação. Ainda assim agendamos uma segunda conversa para a semana seguinte.

Ainda que contasse com sua falta, na semana seguinte, diante de sua ausência, liguei para confirmar o horário. Ao telefone, despretensiosamente, respondeu que "não havia ninguém com aquele nome". Novamente me senti trapaceado, enquanto ele parecia se divertir com o meu comprometimento em esperá-lo no horário marcado. 
Aprofundando-nos na análise do encontro com o paciente, pode-se aventar que os sentimentos vivenciados pelo psicopatologista sejam expressão de uma ressonância empática com o paciente. Sua atitude usualmente desonesta, a agressividade contra as mulheres quando enciumado, a falta de comprometimento com os honorários, todos estes comportamentos poderiam ter como fundo vital a ameaça constante de um mundo descomprometido, agressor e impessoal, despertando assim uma postura predatória frente ao mundo.

O melhor enquadre nosológico até aqui, segundo os critérios da DSM-IV (APA, 2002) e da CID-10 (OMS, 1993), seria o de "Transtorno de personalidade anti-social": incapacidade de adequar-se às normas sociais implicando atos ilícitos, propensão para enganar, mentir, ludibriar, irresponsabilidade, desrespeito pela segurança, irresponsabilidade consistente, ausência de remorso.

Ressalte-se, no entanto, que não pretendemos afirmar, peremptoriamente, baseados unicamente nos relatos do paciente e na experiência vivida em um único encontro, que estamos diante de um "Transtorno de personalidade anti-social", mas talvez que estamos diante de uma essência relacional compatível com a psicopatia, nos termos já apontados anteriormente. Acreditamos, no entanto, que as vivências apontadas e relatadas pelo paciente, se idênticas a si mesmo ao longo do tempo, seriam compatíveis com este diagnóstico.

Se de um lado entendemos que a personalidade anti-social ou psicopática é "fria de alma", como proposto por Schneider (1943), por outro podemos imaginar, buscando a "positividade no negativo" proposta por Blankenburg, que esta frieza talvez seja a expressão de características repulsivas (conservadoras) frente aos temores do devir, inerentes à vida relacional, como a possibilidade de vivências de injustiça e sofrimento nas relações afetivas sociais, especialmente quando mais íntimas.

O contato interpessoal com tal paciente exige do psicopatologista uma postura receptiva, aberta, aparentemente ingênua em relação às possibilidades de ser enganado, ao mesmo tempo que uma atenção especial ao risco de ser trapaceado - seja através das regras estabelecidas para a ocorrência dos encontros, seja pelos sentimentos vividos durante o tratamento. É necessário estar disposto a viver o risco do engodo sem que este limite o interesse pelo encontro, pois a partir deste encontro poder-se-ia criar as condições para a expressão última dos fatores que alimentam as características repulsivas (Canguilhem, 2009) que estancam o movimento propulsivo de sua existência. 
Não objetivamos aqui caminhar por uma interpretação única que tente explicar em absoluto seu comportamento anti-social, mas sim ampliarmos a possibilidade de compreensão empática das vivências presentes no encontro, que podem ajudar a estabelecer um melhor entendimento dos obscuros (para ambos) interesses daqueles nos procuram.

Passemos agora à análise de um caso de características aparentemente semelhantes.

\section{Vinheta clínica II}

Um adolescente de 16 anos está internado em casa de custódia para menores infratores por envolvimento com o crime.

Após dois meses na unidade de internação, é encaminhado para atendimento psiquiátrico após suposta tentativa de suicídio pendurando-se na trave de futebol com uma blusa atrelada ao pescoço, no pátio onde são realizadas atividades recreativas e educacionais durante o dia, e onde vários outros adolescentes realizavam atividades esportivas supervisionadas no mesmo momento.

Durante a entrevista conta que está envolvido com o crime desde os 8 anos de idade. Diz que "com uma arma na mão vira um pitbull sem coleira", e quando questionado conta não ter arrependimento dos crimes cometidos, mesmo que tenham gerado esta internação. Acredita que suas vítimas são as responsáveis por sua internação, e que "elas pagarão por isto quando sair da internação". Já estivera internado na mesma unidade pelo mesmo motivo, e voltou a delinqüir assim que foi extinguida a internação.

Conta também que faz uso abusivo de drogas (maconha e cocaína), sem preferência por nenhuma delas, desde os 8 anos de idade. Nesta época deixou de freqüentar a escola e passava os dias nas ruas roubando ou usando drogas. O adolescente não adquiriu um padrão de uso de drogas compatível com o diagnóstico de dependência, e não parece haver relações causais entre o uso de drogas e o envolvimento com o crime, apesar de simultâneas.

Seu pai falecera havia dois anos, e quando questionado quanto ao motivo de sua morte disse não querer falar no assunto, rispidamente, não expressando tristeza nem qualquer outro sentimento que pudesse dar margem a uma 
compreensão empática de seus motivos. Sua mãe tem emprego de pouca qualificação, e tem 4 irmãos, sendo um mais velho e outros três mais novos. $\mathrm{O}$ mais velho era maior de idade e estava preso por envolvimento com roubo à mão armada no momento da avaliação.

Durante a internação, envolveu-se em episódio de discussão com a professora em sala de aula, e foi mandado para fora da sala. No entanto, a professora pediu desculpas logo depois, aparentemente por ter se excedido na discussão, mas o adolescente diz não ter aceitado suas desculpas, afirmando que "desde que inventaram a desculpa ninguém morre mais".

Chamado à sala para uma entrevista inicial, mostra-se algo inquieto, não senta na cadeira, mas mexe tranquilamente nos objetos dispostos na sala. Sem demonstrar irritação ou agressividade, não aceita as orientações mais simples propostas, como se sentar ou não mexer nos objetos sobre a mesa. Apesar de aparentemente desinteressado pela conversa, não mantendo interação visual com o entrevistador, mostra-se bastante atento às perguntas, respondendo com rapidez e objetividade. Não há sinais de prejuízos cognitivos da memória ou inteligência, e parece ser um jovem esperto, pois entende facilmente o intuito da entrevista e percebe com clareza os estímulos do ambiente, respondendo aos mesmos prontamente. Pode-se dizer que, apesar de sua aparente displicência na conversa, instiga o entrevistador com suas respostas desinvestidas de afeto. Questionado sobre a tentativa de suicídio, esclarece que fez isso porque estava chateado por não ter recebido visita da mãe, sem demonstrar, novamente, tristeza ou outro afeto que pudesse despertar uma compreensão empática imediata. Não se pode dizer, até este momento, que seja "frio de alma", mas talvez indiferente às minhas intenções com ele ou às possibilidades de tratamento que pudessem emanar do atendimento. Também não parece demonstra preocupação em simular um bom comportamento, como fazem muitos outros jovens nestas condições. Mostra-se basicamente indiferente frente às condições de sua internação, seja no que tange às instalações físicas ou às pessoas responsáveis por sua tutela na unidade.

Ainda que haja impossibilidade de afirmar um diagnóstico neste momento, seja pelas limitadas informações, seja pela idade do paciente, a análise do encontro sugere novamente a presença de traços psicopáticos, tal qual no caso anterior. Evidencia-se, ao longo de seu relato biográfico e durante todo o encontro, um padrão repetitivo de indiferença pelos sentimentos alheios, irresponsabilidade, desrespeito por normas e regras e incapacidade de sentir culpa e aprender com experiência. 
Nota-se que há, no entanto, em oposição à vinheta clínica I, e a despeito de sua aparente insensibilidade afetiva, uma atmosfera de simpatia pelo jovem, que desperta no entrevistador um interesse genuíno por suas histórias, mesmo que limitadas em conteúdo às vivências de criminalidade.

O interesse pelo entrevistador pode ser compreendido, neste caso, como expressão da empatia imediata com as limitações impostas por sua biografia: ambiente familiar marcado pela criminalidade, envolvimento bastante precoce com o uso de drogas, vivência de rua, longas internações em casas de custódia. Este cenário parece impor claras limitações ao desenvolvimento do adolescente frente às suas possibilidades existenciais.

Entendemos que, se o adolescente imputasse ao meio social onde vive a responsabilidade pelas agruras de sua vida, ou a alguma entidade religiosa, ou então a si mesmo "por procurar más companhias", poderíamos rapidamente dispensar este relato, sem atribuir maior significado para um aprofundamento psicopatológico, já que estes são relatos comuns e de certa forma repetidos sem maior reflexão por adolescentes infratores.

No entanto, o relato pouco habitual de ódio de suas próprias vítimas por sua internação, aliado à sua aparente indiferença pela entrevista, sugere que o ódio relatado esteja mais à superfície das camadas afetivas do que na vinheta I, e estabelece assim uma relação mais vívida e intensa com o entrevistador. Neste caso, o ódio é "o negativo do positivo", isto é, é a resposta imediata a um mundo que convoca, a todo tempo, uma resposta imediata para que não seja aniquilado.

Nota-se que, enquanto na vinheta I observamos uma relação predatória com o mundo, desprezando as pessoas com que convive mesmo que de forma silenciosa, neste caso observamos uma relação parasitária com o mundo circundante, em que o indivíduo precisa do outro para sustentar sua existência, seja roubando, perturbando ou chamando a atenção para si em atos mais plásticos.

Não se pode falar aqui de frieza afetiva, ou seja, de hiporreatividade, mas sim de hiperreatividade, e deste ponto de vista as tipologias poderiam ser consideradas antagônicas, ainda que sujeitas a categorias diagnósticas semelhantes do ponto de vista criteriológico-sintomatológico.

\section{Observações finais}


Entendemos que as experiências vividas no contato interpessoal no encontro com um paciente, e as reflexões advindas deste encontro são os instrumentos mais preciosos de que dispomos para a compreensão das personalidades normais ou patológicas. Afinal, a personalidade não se materializa e não assume suas formas características próprias de outra forma que não na relação dual. É no contato com o mundo e com os outros que alguém evidencia sua essência, e sendo assim esta não pode ser avaliada de outra forma. Assim, a presunção da independência do observador é uma falácia especialmente quando se fala do estudo das personalidades. Estas jamais poderão ser objeto de uma investigação que não contemple as relações com o outro e os fenômenos provenientes deste encontro.

As tipologias dialéticas propostas por Blankenburg (2007) permitem um aprofundamento dentro das tipologias a partir da busca de características positivas na expressão de características negativas associadas a elas. Assim, ainda que entendamos os transtornos da personalidade como condições existenciais patológicas pela força de suas características repulsivas, a busca do positivo proposta por este autor ajuda a compreender estes modos de ser-nomundo, e desta forma estabelecer o melhor tratamento a partir desta compreensão.

Em oposição a uma busca desenfreada por sintomas para o estabelecimento do critérios diagnósticos, esta perspectiva propõe a pesquisa das qualidades do encontro com o paciente como forma de conhecer sua essência e desta maneira poder melhor ajudá-lo.

Ainda que permita um diálogo possível com as modernas nosografias, a psicopatologia fenômeno-estrutural ambiciona um aprofundamento psicopatológico das categorias diagnósticas concebidas atualmente, utilizandose da análise da experiência vivida no encontro com os pacientes, assumindo tanto a função de técnica, enquanto capacidade de reproduzir com maior afinco determinados padrões de funcionamento, quanto epistemológica, enquanto aquela que se propõe a questionar os fundamentos do conhecimento psicopatológico utilizados no exercício da psiquiatria contemporânea.

Note-se, ainda, que a ambição deste estudo não se limita a validar ou invalidar um diagnóstico específico, mas estudar as possibilidades de compreensão de fenômenos habitualmente percebidos e associados ao termo "psicopatia", através da análise da intersubjetividade presente no encontro. Acreditamos abrir, assim, possibilidades de compreensão fenomenológica destas vivências, tidas aqui como patológicas, a partir dos critérios de 
Canguilhem, mas permeáveis à compreensão a partir das tipologias dialéticas de Blankenburg.

Por último, destacamos que existem diversos outros estudos fenomenológicos de grande relevância para a compreensão fenomenológica do daquilo que atualmente chamamos de transtornos da personalidade, pois apresentam características semelhantes com as propostas diagnósticas atuais. Entre eles destacamos os estudos de Tellenbach (1961) sobre o typus melancholicus, de Binswanger (1972), que parece fazer uma leitura fenomenológica para modos de ser-no-mundo que possivelmente seriam enquadrados nos dias de hoje entre os transtornos de personalidade do cluster A pela DSM-IV (APA, 2002), e de Fuchs (2007), sobre os transtornos de personalidade borderline. O estudo aqui apresentando é mais uma tentativa de contribuição neste campo, um esboço para futuros mergulhos mais profundos em direção às essências das naturezas humanas e suas variantes anormais e patológicas.

\section{Referências bibliográficas}

Associação Psiquiátrica Americana (APA). (2002). Manual Diagnóstico e Estatístico de Transtornos Mentais (DSM-IV-TR). (Quarta Edição - Revista). Porto Alegre: Artmed.

Binswanger, L. (1972). Tres formas de la existencia frustrada. Buenos Aires: Amorrortu.

Blankenburg, W. (2007). Wie weit reicht die dialektische Betrachtungsweise in der Psychiatrie?. In: Psychopathologie des Unscheinbaren. Editora Parodos.

Castellana, G. (2008). O Contato interpessoal na perspectiva fenomenológica.In: Messas, G. (org). Psicopatologia Fenomenológica Contemporânea. São Paulo: Roca.

Canguilhem, G. (2009). O normal e o patológico. (6 $6^{\mathrm{a}}$ edição revista). Rio de Janeiro: Editora Forense universitária.

Dorr, O. (1995). Perspectiva fenomenológica de los transtornos de personalidad. In: Psiquiatria antropológica: contribuiciones a uma psiquiatria de orientacion fenomenológica-antropologica. Santiago de Chile: Editorial universitária.

Fuchs, T. (2007). Fragmented selves: temporality and identity in borderline personality disorder. Psychopathology, v. 6, n 40, pp. 379-87. 
Hare, R. et al. (1991). Psychopathy and the DSM-IV criteria for antisocial personality disorder. J Abnorm Psychol, v 3, n 100, pp. 391-8.

Jaspers, K. (2005). Psicopatologia Geral: psicologia compreensiva, explicativa e fenomenologia.(vol 2, 8. ${ }^{\text {a }}$ ed). S. Paulo: Livraria Atheneu.

Kraus, A. (1987). Comparacion fenomenológica entre la estrutura de la histeria y de la melancolia. In: Barcia, D. (ed). Psiquiatria antropológica. España: Secretariado de publicaciones e intercambio cientifico de la Universidade de Murcia.

- (1994). Phenomenological and Criteriological Diagnosis: different or complentary? In: Philosofical Perspectives on Psychiatric Diagnostic Classification. The John Hopkins University Press.

. (2003). How can the phenomenological anthropological approach contribute to diagnosis and classification in psychiatry?. In:Nature and Narrative: an introduction to the new philosophy of psychiatry. (International Perspectives in Philosophy \& Psychiatry). Oxford University Press.

Lanteri-laura, G. (1982).Phenomenology and a critique of the foundations of Psychiatry. In: Koning, A; Jenner, F. Phenomenology and Psychiatry. London: Academic Press.

Nagel, T. (1991). What is it like to be a bat?. In:Rosenthal, D. (ed.). The nature of mind. New York: Oxford University Press.

Organização Mundial da Saúde (OMS). (1993). CID-10:Classificação Estatística Internacional de doenças e problemas relacionados à saúde (10 a ed, vol 2). São Paulo: EDUSP.

Shine, S. (2005). Psicopatia. Coleção Clínica Psicanalítica. São Paulo: Casa do Psicólogo.

Schneider, K. (1943). Las Personalidades Psicopaticas. (1 ${ }^{\mathrm{a}}$ edicion). Madrid: Ediciones Morata.

Tatossin, A. (2006). A fenomenologia das psicoses. São Paulo: Editora Escuta.

Tellenbach, H. (1961). Melancholy. Pittsburgh: Duquesne University Press.

Wyrsch, J. (1957). La persona del esquizofrénico. En: Lopez-Ibor, J. (ed).

Symposium sobre la esquizofrenia. Madrid: CSIC. 